УДК 338.24.0/1(091)

DOI: $10.21779 / 2500-1930-2021-36-2-93-102$

\title{
К.М. Магомедалиева
}

\section{Эволюция управленческой мысли за рубежом}

Дагестанский государственный университет; Россия 367000, 2. Махачкала, ул. М. Гаджиева 43a; karina557@mail.ru

В статье рассматривается эволюция управленческой мысли за рубежом, формирование и развитие научных школ управления. Управление является одним из основополагающих видов деятельности в современном обществе и в системе разделения труда. Управленческая деятельность имеет свою специфику, а в системе человеческих, государственных, производственных отношений управление - многогранное, сложное явление. Современный управленец должен обладать определенным стилем и методологией управленческой деятельности, знать основные научные подходы, которые успешно применяются в управленческой практике. Поскольку мы наблюдаем, какими быстрыми темпами развиваются научно-технические, технологические процессы, различные формы организации труда во всех сферах общества, конкурентоспособность, наука управления становится востребованной, и управление на любом уровне требует научного подхода, объяснения, обоснования и философского осмысления.

Ключевые слова: управление, научные школь, эволючия управленческой мысли, стиль и методология управленческой деятельности.

Человеческое общество с момента своего возникновения столкнулось с необходимостью совместной деятельности людей. Независимо от типа хозяйствования (присваивающий тип или производящий), от формаций, цивилизаций, культур, на любых этапах развития, требовалось наличие определенных структур, способных организовывать людей и управлять их деятельностью. Сегодня управление в системе разделения труда имеет свою специфику и становится одним из основополагающих видов деятельности в современном обществе. «Управленческая деятельность определяется как деятельность по обеспечению совместной деятельности, строящейся по иерархическому (управляемому) принципу» [1, с. $438-441]$.

Существует множество определений понятия управление, которые используются в зависимости от изучаемого объекта. Лаконичным на наш взгляд является определение известного на весь мир управленца Ли Якокка, который считает, что управление - это настраивание людей на труд [3]. Наиболее приемлемым в контексте нашей темы может быть определение, когда под управлением понимается функция организованных систем, направленная на обеспечение и сохранение их структуры, поддержание режима функционирования и реализации задач по достижению цели деятельности [6].

Хотя концепции управления появились в европейских странах еще в XVIXVIII веках, формирование управления как научной дисциплины и складывание науки управления произошли в начале $\mathrm{XX}$ века. Говоря об эволюции управленческой мысли за рубежом, акцентирую внимание на формирование и развитие школ научного управления на протяжении всего XX века и их идеи актуальны в XXI веке.

Современное общество является сложно структурированной социальной системой и в связи с этим управление как форма деятельности (независимо от уровня и масштаба организации) становится многогранной, что требует от управленцев теоретических знаний и практических навыков, которые должны привести к достижению целей. 
Сегодняшнему управленцу необходимо обладать определенным стилем и методологией управленческой деятельности, знать основные научные подходы, которые успешно применяются в управленческой практике. Учитывая, какими быстрыми темпами развиваются научно-технические, технологические процессы, различные формы организации труда во всех сферах общества, конкурентоспособность, наука управления становится востребованной, и управление на любом уровне требует научного подхода, объяснения и обоснования.

Изучению управленческой мысли посвящено большое число исследований российских и зарубежных авторов. Первая публикация появилась в 1911 г. - книга Ф.У. Тейлора «Принципы научного управления», которую традиционно считают началом признания управления наукой и самостоятельной областью исследования. Научное управление наиболее тесно связано с работами Фрэнка и Лилиан Гилбретов, ???и Генри Гантта, Анри Файоля, Джеймса Д. Муни, А.К. Рейли, М. Вебера.

Прежде чем приступить к изложению истории появления и характеристик школ научного управления за рубежом, хотелось бы сделать краткий экскурс в историю становления развития самой управленческой мысли.

Управление как один из видов человеческой деятельности появилось еще в древности. Мы знаем, что первобытные люди жили организованными группами, родами, племенами, руководство которыми мог осуществлять один человек, а с появлением древних цивилизаций увеличились масштабы хозяйственной деятельности и соответственно «управленческий персонал». Первый трактат об управлении коллективом под названием «Поучение Птахотеппа» появился в Древнем Египте. В последующем китайский философ Конфуций предложил первую теорию управления. Древнегреческий философ Сократ сформулировал принцип универсальности управления и высказал мысль, что необходимо поставить нужного человека на нужное место и добиться выполнения поставленных перед ним задач. Древнегреческий философ Ксенофонт считал, что управление людьми является особым видом искусства.

Вопросам управления уделяли внимание Платон и Аристотель, а в эпоху Возрождения - Никколло Макиавелли в своей работе «Государь» коснулся вопросов стиля работы руководителя, организации его труда, взаимоотношений руководителей и подчиненных.

Серьезный толчок развитию практики и теории управленческой мысли дала эпоха Нового времени, когда по Европейским странам прокатилась волна промышленных революций. В это время появились теоретические исследования А. Смита, У. Петти, Д. Рикардо и социальные эксперименты Р. Оуэна в области управления. Эти труды сыграли большую роль в становлении науки управления.

В формирование теории управления свой вклад внесли и классики марксизма К. Маркс и Ф. Энгельс, хотя они непосредственно не занимались проблемами управления, но созданные ими методы исследования повлияли на развитие управленческой науки. Анализ становления капиталистического общества и форм хозяйствования позволил К. Марксу сделать вывод, что результатом разделения труда явилось обособление управления, которое стало рассматриваться в качестве особой функции любого совместного труда. Ф. Энгельс сделал акцент на том, что следует различать управление вещами и управление людьми. От этого тезиса в дальнейшем будут отталкиваться многие ученые в своих исследованиях. Заслуга К. Маркса в том, что он обосновал стихийные и сознательные типы управленческих процессов и их возможную взаимосвязь. «Стихийные процессы имеют место в любом обществе и выражаются в слепой игре случая, например, в условиях рыночной стихии. Сознательные факторы управления выражаются в 
целенаправленной деятельности людей, во влиянии общественных институтов, в функционировании организаций, обеспечивающих порядок и относительную эмансипацию от случая, произвола, стихии» [2, с. 356-357]. Но только в начале XX века после публикации книги У. Тейлора «Принципы научной организации управления» появилась первая школа научного управления и происходит формирование науки управления.

Первой школой научного управления была классическая школа, которая формировалась в 20-х годах XX века. На протяжении 30 лет шли разработка и применение основных идей этой школы на производстве. Эта школа уделила внимание изучению вопросов важности роли и функции управленца. Большая заслуга в становлении этой школы принадлежит американскому инженеру У.Ф. Тейлору (1856-1915), которого считают отцом управленческой науки. Он возглавил движение научного управления и в своих работах «Управление фабрикой» (1903) и «Принципы научного менеджмента» (1911), в «Показаниях перед специальной, комиссией Конгресса» (1912) изложил методы научной организации труда. Разработка этих методов основана на исследованиях движений рабочего с помощью хронометража, стандартизации приемов и орудий труда. У. Тейлор разработал и внедрил принцип пооперационного разделения труда и рационализации трудовых функций работников. Он был не только практик, но и теоретик, и в теорию управленческой науки он выдвинул идею о необходимости согласования интересов работодателей и наемных рабочих. Главный принцип управления которым руководствовался У. Тейлор, был следующий: если я могу отобрать подходящих людей для работы, подготовить их на научной основе, стимулировать их и соединить человека и его работу, тогда увеличится и производительность. Таким образом, ему удалось разработать методологические основы нормирования труда, внедрить в практику научные подходы подбора, расстановки и стимулирования рабочих и стандартизации рабочих операций.

У. Тейлор свое видение роли управления высказал в тезисе: «Главнейшей задачей управления предприятием должно быть обеспечение максимальной прибыли для предпринимателя в соединении с максимальным благосостоянием для каждого занятого на предприятии работника» [8, с. 24].

Система управления, которая сложилась на производстве к началу XX века, по мнению У. Тейлора, имела ряд недостатков. Эти недостатки связаны были с тем, что рабочие не были заинтересованы в накоплении своих навыков, т. е. в профессионализме, рабочих не поощряли материально, что не вызывало у них стремления лучше работать. У. Тейлор пытается поменять ситуацию в системе управления и считает, что администрация должна к проблемам управления подходить с научной позиции, т. е. основательно изучить производственный процесс и разбить этот процесс на отдельные узконаправленные операции и подбор кадров на эти рабочие места оставить за собой. Если раньше сами рабочие определяли свое место работы, то теперь это делает администрация. Каждому работнику задается определенная норма выработки, которая стимулируется дополнительной оплатой за перевыполнение этой нормы [8, с. 24-35]. Таким образом, управленческие механизмы У. Тейлора основывались на принципе разделения труда, сдельной оплаты и контроля со стороны администрации. Теперь все вопросы, связанные с процессом производства были в компетенции администрации. Рабочие становятся объектом управления. Здесь необходимо вспомнить А. Смита и Ч. Баббиджа, которые раньше У. Тейлора предложили принцип разделения труда.

У. Тейлор пытался внедрить принцип разделения труда, в практику конкретных предприятий и таким образом, увеличить производительность труда, через мотивацию работников, а не через жесткий контроль со стороны администрации. Как пишет Б.А. 
Сосновский, «Ф.У. Тейлор (1856-1915) неоднократно и отчётливо призывал, например, к принудительному «сотрудничеству» рабочих и хозяев, формулируя разрозненные практические советы, рекомендации и психолого-педагогические управленческие приёмы на уровне «здравого смысла» [5, с. 159].

Идеи У. Тейлора были воплощены в жизнь его последователями, одним из них был Генри Форд - создатель первой автомобильной империи, которому удалось соединить технологию массового конвейерного производства с авторитарным научным подходом в управлении.

В становлении науки об управлении определенную роль сыграли супруги Фрэнк и Лилиан Гилбреты, которые проводили исследования в области трудовых движений и разработали научные принципы организации рабочего места. Главное внимание было уделено рационализации труда, при которой учитывались условия рабочего места и интересы персонала. Ф. Гилбрет исследовал процесс повышения производительности труда без приложения усилий и развил идею Ф.У. Тейлора о нормативах затрат времени на каждый элемент трудовых операций. Фрэнк и Лилиан Гилбреты разработали план продвижения для рабочих, включающий в себя три последовательные части. Согласно этому плану рабочий должен был делать свою работу, обучить своего последователя, получить навыки по продвижению к более сложной работе. Они считали, что эффективность производства напрямую связана с системой планирования и управления.

В своей работе «Основы научного менеджмента» Гилбреты показали достоинства использования «научных методов менеджмента». «Л. Гилбрет ввела новые методы в исследование управления. По ее мнению, научные исследования менеджмента должны проводиться на основе анализа и синтеза. При помощи анализа один из элементов управления разбивается на составные части, а потом в процессе синтеза они воссоединяются, но в новый комплекс управления входят уже только те части, которые необходимы для эффективного решения задачи» [9].

Представители классической школы в написании своих работ в основном исходили из личного опыта работы на производстве, т. е. из личных наблюдений, а не с точки зрения научной методологии, и стремились создать универсальные методы управления производством.

Дальнейшее развитие классической школы управления происходило в двух основных направлениях - рационализация производства и исследование общих проблем управления, и связано оно с именами Г. Эмерсона, А. Файоля, Л. Урвика, М. Вебера, Г. Форда.

Эмерсон Г. в своей работе «Двенадцать принципов производительности» (1911) сформулировал принципы управления предприятиями, главными из которых были: точно сформулированные цели управления, к достижению которых должны стремиться все, как руководитель, так и подчиненные независимо от уровня управления. Каждый новый процесс необходимо анализировать с позиций перспективных целей. Установить время и последовательность выполнения операций, закрепить правила выполнения операций, инструкции, вознаграждение и поощрение работников. Г. Эмерсон указал целесообразность комплексного подхода в решении вопросов управления и производства.

С возникновением административной школы, как одной из разновидностей классической школы, началось вырабатывание подходов к совершенствованию управления организацией в целом, т. е. акцент был сделан на вопросах роли и функции управления. Была сделана попытка определить суть работы управляющего и через это 
выявить эффективные методы управления. Начало разработке идей этой школы было заложено А. Файолем. В своем основном труде «Общая и промышленная администрация» (1923) А. Файоль разработал общий подход к анализу деятельности администрации. На этой основе он сформулировал некоторые строго обязательные принципы администрирования. А. Файоль разделил процесс управления на 5 основных функций: планирование, организация, подбор и расстановка кадров, мотивация и контроль. Этот подход используется на производстве и в современный период. Принципы А. Файоля являются принципами администрирования, поэтому и школа получила такое название.

\section{Основные принципы управления по Файолю:}

1) Разделение труда. Этот принцип применим не только в сфере производства, но в и управленческой сфере. Разделение труда непосредственно связано со специализацией. Цель разделения труда - выполнение большего объема работы с лучшим качеством при затрате тех же усилий, что достигается путем сокращения количества целей, на которые направляются внимание и усилия работника. Разделение труда эффективно до определенных размеров, при достижении которых оно не приносит желаемых результатов.

2) Полномочия и ответственность. Полномочия напрямую связаны с ответственностью. Полномочия связаны с властью и возможностями распоряжаться ресурсами и организовать сотрудников на выполнение поставленных целей. Власть связана с ответственностью.

3) Дисциилина. Дисциплина предполагает соблюдение соглашений, заключенных между предприятием и его работниками. В случае нарушения дисциплины к работникам могут применяться санкции. Выработка таких соглашений, связывающих фирму и ее работников и определяющих формальные дисциплинарные требования, должна быть одной из главных задач руководителей отрасли. Дисциплина предполагает также справедливое применение санкций.

4) Единоначалие (единство распорядительства). Работник должен получать распоряжения и указания от своего непосредственного руководителя. Кроме того, он должен уважать авторитет руководителя.

5) Единство направления (дирекичи). Один руководитель и одна программа для совокупности операций, преследующих одну и ту же цель. Каждая группа, действующая в рамках одной цели, должна быть объединена единым планом и иметь одного руководителя.

6) Подчиненность личных (индивидуальных) интересов общим. Интересы одного работника или группы работников не должны преобладать над интересами организации и должны быть направлены на выполнение интересов всего предприятия.

7) Вознаграждение персонала, т. е. цена оказываемых услуг. Она должна быть справедливой и по возможности удовлетворять как персонал, так и организацию, как нанимателя, так и работника. Чтобы обеспечить верность и поддержку работников, их работу необходимо справедливо вознаграждать.

8) Централизация. На предприятии должно быть достигнуто определенное соответствие между централизацией и децентрализацией, которое зависит от его размеров и конкретных условий деятельности. Однако степень централизации варьируется в зависимости от конкретных условий, в связи с чем возникает вопрос об оптимальном соотношении централизации и децентрализации организации.

9) Скалярная иепь (иерархия). Скалярная цепь - это ряд руководящих должностей, начиная с высших и заканчивая низшими. Скалярная цепь определяет подчинение 
работников. Иерархическая система управления является необходимой, но если она наносит ущерб интересам предприятия, то ее необходимо усовершенствовать.

10) Порядок. Каждый работник должен иметь свое рабочее место, обеспеченное всем необходимым. Для этого руководитель должен хорошо знать своих подчиненных и их потребности.

11) Справедливость. Справедливость - это сочетание доброты и правосудия. Работник, чувствующий справедливое отношение к себе, испытывает преданность к фирме и старается трудиться с полной отдачей.

12) Стабильность рабочего места для персонала. В успешных компаниях управленческий персонал является стабильным. Высокая текучесть кадров является причиной и следствием плохого состояния дел. Для предприятия наиболее предпочтительными являются работники, которые держатся за свое место.

13) Инициатива. Инициатива - это разработка плана и успешная его реализация. Высокая текучесть кадров снижает эффективность организации, поэтому менеджер пусть даже среднего звена, который дорожит своей работой, лучше, чем тщеславный управленец, который думает только о своем имени.

14) Корпоративный дух. Сила предприятия в гармонии («единении») всех работников предприятия. Файоль указывал на недопустимость использования в управлении принципа «разделяй и властвуй». Напротив, считал он, руководители должны поощрять коллективизм во всех его формах и проявлениях. Желание разработать план и обеспечить его успех дает организации процветание [4].

Если проанализировать подход А. Файоля, можно сделать вывод, что он рассматривает управление как субъект-объектное отношение, где субъектом выступает руководитель предприятия, а объектом - исполнитель, т. е. подчиненный. А. Файолю удалось рассмотреть управление как универсальный процесс, состоящий из нескольких взаимосвязанных функций, таких, как планирование и организация. Это был его существенный вклад в теорию управления. Как утверждал А. Файоль: «Управлять - значит, вести предприятие к его цели, извлекая максимальные возможности из всех имеющихся в распоряжении ресурсов» [11, с. 9].

Основные положения А. Файоля развил и углубил Л. Урвик. Он уделил внимание разработке принципов формальной организации, согласно которым вначале следует детально разработать структуру организации, а затем подобрать специалистов, в наибольшей степени соответствующих требованиям структуры. Следующими необходимыми положениями были: создание специального и генерального штабов, которые должны подготовить и передать приказы руководителя; сопоставимость права и ответственности; контроль подчиненных; специализация управленцев по признаку цели, операции, типу потребителя либо географическому признаку и определенность. То есть в каждой организации должны быть письменно определены права, обязанности, ответственность, взаимоотношения и взаимосвязи с другими лицами. Следовательно, классическая теория управления рассматривала управление как систему нормированных отношений, полностью поддающихся рационализации. Такой подход мы встречаем и у М. Вебера в его концепции об «экономическом» (рациональном) человеке и идеальной бюрократической организации, предложенный им в 1921 году.

Вебер М. дал характеристику идеальных типов господства и выдвинул положение, согласно которому бюрократия является самой эффективной формой человеческой организации. Бюрократия - это порядок, устанавливаемый правилами. Хотя М. Вебера и относят к административной школе управления, но его концепция опирается на культурологическую интерпретацию организационных процессов, чем он и отличается от 
большинства представителей этой школы. «Отдельные исследователи относят его к особому направлению в теории управления, связанному с культурологическим пониманием «машинной модели организации»»» [10].

Если сделать вывод по классической школе (научной и административной), можно сказать, что основной ее чертой является поиск способа достижения эффективности производства. Целью представителей этой школы было обнаружить тот единственно приемлемый и совершенный метод управления. Классическая школа является одной из первых школ в мировой управленческой науке. Как отмечают А.В. Тебекин и В.Б. Мантусов в своей монографии «Управление организацией: теоретико-методологические основы, функциональные задачи, технологии, прикладные аспекты применения»: «Ф. Тейлор, А. Файоль, Г. Эмерсон, М. Вебер сформулировали базовые принципы классического научного управления: отчетливая постановка цели, экономический подход, четкое разделение труда, специализация работы, научный отбор кадров, полный контроль и учет, стандартизация операций, поощрение инициативы, индивидуальная ответственность за решение, иерархичность управления, подчиненность индивидуальных интересов общим» [7, с. 34].

Рассмотренная нами классическая школа не является единственной школой научного управления. Хотя представители научного управления и признавали значимость человека в процессе производства, но не уделяли внимание человеческому фактору, а лишь сводили все к экономическому стимулированию и справедливой оплате. В ответ на этот подход в 30-40-х годах XX века зародились движение за человеческие отношения и школа психологии и человеческих отношений, которая иногда называется неклассической школой. С 1950-го по настоящее время она называется Бихевиористской школой. По мнению Б.А. Сосновского, «оформление психологии труда как востребованной и развивающейся отрасли науки произошло в начале XX века в связи с резким возрастанием промышленного производства и хронологически связано с публикацией известной работы Г. Мюнстерберга «Психотехника» (1910). Человек-работник постепенно становится предметом целенаправленных, собственно психологических и усложняющихся исследований. Общепризнанный основатель «научной организации труда» $[5$, с. 158$]$.

Это был определенный прорыв в управлении. В его основу легли достижения в области психологии и социологии, поэтому теперь был важен сам человек, а не его работа. Поменялся подход в управлении, теперь уже забота о каждом работнике выходила на первый план. Необходимо отметить, что проблемы влияния психологических факторов на производство в свое время разрабатывала Л. Гилбрет, хотя мы ее заслуги относим к классической школе управления.

Движение за человеческие отношения связывают с именами ученых Мэри Паркер Фоллетт и Элтона Мэйо, которые внесли большой вклад в развитие школы психологии и человеческих отношений в управлении. Фоллетт, первая, кто определил управление как «обеспечение выполнения работы с помощью других лиц». На заводе «Уэстерн Электрик» в Хотторне проводились знаменитые эксперименты Элтона Мэйо, который обнаружил, что хорошая заработная плата и четко разработанные рабочие операции не всегда приводят к повышению производительности труда, как это считали представители школы научного управления. Для работников важно было взаимодействие друг с другом, больше чем рациональное управление со стороны руководителя. Это означало, что работники могли намного сильнее реагировать на давление со стороны коллег по группе, чем на желания руководства и на материальные стимулы. В последующем эксперименты А. Маслоу и других психологов подтвердили это. В основе 
поведения людей и мотивы их поступков больше были связаны с различными социальными потребностями, которые не всегда можно удовлетворить с помощью денег.

Исходя из этих исследований, представители психологической школы считали, что если руководители предприятий будут проявлять большую заботу о своих работниках, то и производительность труда будет намного выше. Забота о подчиненных, прежде всего, проявлялась в предоставлении возможности налаживать межличностное общение людей на работе.

Школа психологии и межличностных отношений развила изучение труда с социальной стороны. Было положено начало управлению персоналом, для которого оптимальной является возможность налаживания максимально слаженных отношений между управленцами и сотрудниками для достижения целей организации. Представителями психологической школы была подвергнута критике субъект-объектная схема управления и вместо доминирующего фактора «экономический» человек был предложен «социальный» человек. И теперь санкции первичной социальной группы и авторитет неформального лидера имели большее значение, чем формальные правила, установленные работодателями. Этот стиль управления основывался на результатах эмпирических исследований. В результате исследований был сделан вывод, что неформальные связи на производстве и в других социальных общностях приводят к сплачиванию групп, что влияет на благоприятную атмосферу и на производительность труда. К социально-психологическим идеям близка и теория мотивации, которая занимает существенное место в социологии управления.

В разработку теории мотивации, на начальном этапе развития, большой вклад внесли А. Маслоу, Ф. Херцберг, Ч. Бернарда, Л. Уорнер. Суть этой теории обоснование необходимости формирования мотивов трудовой деятельности. Мотив деятельности мобилизует людей и должен привести к экономическому успеху. Одним из важнейших средств достижения управленческого эффекта стало рассматриваться и привлечение работников к участию в управлении в качестве держателей акций.

Развитие теории поведенческого направления в более поздний период связано с такими исследователями, как Р. Лайкерт, К. Арджирис, Д.М. Грегор, Ф. Герцберг. Помимо вопросов мотивации они изучали и характер власти и авторитета, вопросы лидерства, коммуникаций в трудовом коллективе. И таким образом, школа поведенческой науки отходит от принципов школы человеческих отношений. Если школа психологии и человеческих отношений была больше сосредоточена на вопросах межличностных отношений, то школа поведенческих наук уделяла внимание необходимости осознания работником своих возможностей в участии управлении. В 60-х годах XX века в управленческой науке и практике в основном придерживались поведенческого подхода. Главный постулат того времени гласил: повышению эффективности производительности труда, как отдельного работника так и предприятия, в целом поможет правильное применение науки о поведении.

В дополнение к вышесказанному можно добавить то, что тип мотивации в разных ситуациях может себя проявить по-разному. Если мы обратимся к веберовскому пониманию, то в условиях социальных конфликтов в основном играет роль аффективная мотивация, в стандартных условиях коллективной деятельности - традиционная мотивация, в регламентированной экономической деятельности - целерациональная мотивация, а когда возникает вопрос справедливости и служения идеалам, - ценностнорациональная мотивация. Исходя из вышесказанного, мы можем сделать выводы, что:

1. Управление как вид человеческой деятельности имеет многовековую историю становления и развития науки управления. На различных этапах исторического разви- 
тия управленческая мысль обогащалась различными идеями, методами управления, которые возникали в ходе производственной и управленческой деятельности на разных уровнях и масштабах. В связи с этим в начале XX века появились школы научного управления.

2. Появление школ научного управления способствовало превращению управления из «искусства» в науку с научными принципами и подходами.

3. В 60-80-е годы XX в., мы можем заявить, что на Западе, в условиях развитых рыночных отношений произошла управленческая революция, что способствовало еще большему развитию научных школ и идей управления.

\section{Литература}

1. Агафонова М.С., Берегович К.А. Управленческая деятельность: её особенности, структура и характерные черты // Научно-методический электронный журнал «Концепт». - 2017. - T. 2. - C. 438-441. - Режим доступа: http://ekoncept.ru/2017/570086.htm (дата обращения 05.07.2021)

2. Маркс К., Энгельс Ф. Соч. Т. 25, ч. II.

3. https://marketing.wikireading.ru/11427 (дата обращения 08.04.2021).

4. Принципы А. Файоля. - Режим доступа: https://mirznanii.com/a/170129/14printsipov-fayolya/ (дата обращения: 21.07.2021).

5. Сосновский Б.А. Потребностно-смысловые факторы отношения человека к работе // Вопросы управления. - 2020. - № 1 (62). - С. 158-168.

6. Ситуационные теории управления. - Режим доступа: https://portu.ru/osnovyglava2/klassicschool/1613-situatsionnye-teorii-upravleniya (дата обращения: 07.06.2021).

7. Тебекин А.В., Мантусов В.Б. Управление организацией: теоретико-методологические основы, функциональные задачи, технологии, прикладные аспекты применения: монография. - М., 2016. - 309 с.

8. У.Ф. Тейлор Принципы научного менеджмента. - М.: Республика, 1992. $132 \mathrm{c}$.

9. Теория рационализации Ф. и Л. Гилбрет. - Режим доступа: https://portu.ru/elektronm2/1571-teoriya-ratsionalizatsii-upravleniya-f-i-l-gilbret (дата обращения: 21.07.2021).

10. Теория бюрократии М. Вебера. - Режим доступа: (https://mirznanii.com/a/214495/teoriya-byurokratii-vebera/) (дата обращения: 21.07.2021).

11. Управление - это наука и искусство / А. Файоль, Г. Эмерсон, Ф. Тэйлор, Г. Форд. - М.: Республика, 1992. - ???С. 9.

Поступила в редакцию 25 мая 20212. 
UDC 338.24.0/1(091)

DOI: $10.21779 / 2500-1930-2021-36-2-93-102$

\section{The Evolution of Management Thought Abroad}

\section{K.M. Magomedalieva}

Dagestan State University; Russia 367000, Makhachkala, M. Gadzhiev st., 43a, karina557@mail.ru

The article is devoted to the evolution of management thought abroad, the formation and development of scientific schools management. Management is one of the fundamental activities in modern society and in the labor separation system management activities have its own specifics, and in the system of human, government, production relations, a multi-faceted management, a complex phenomenon. A modern managers must have a certain style and methodology of management activities, know the main scientific approaches that are successfully applied in management practice. Since, we see what rapid pace are scientific and technical, technological processes, various forms of labor organization in all spheres of society, competitiveness, management science becomes popular and management at any level requires a scientific approach, explanations and justification and philosophical understanding.

Keywords: management, scientific schools, evolution of management thought, style and management methodology.

Received 25 May 2021 